\title{
New approach to optimize the cost and interconnections of wind turbines using the PSO algorithm
}

\author{
Abdelouahad Bellat ${ }^{1 *}$, Ilham Tyass $^{1}$, Khalifa Mansouri ${ }^{1}$, and Abdelhadi Raihani ${ }^{1}$ \\ ${ }^{1}$ SSDIA Laboratory, Hassan II University of Casablanca, ENSET of Mohammedia, 28830, Morocco
}

\begin{abstract}
Wind power's current growth rates are among the fastest in the world. Research on techniques to make wind farms more energy efficient is warranted for this reason. Optimizing the location of wind turbines within wind farms makes the use of wind energy more efficient and makes wind farms more competitive with other energy sources. The investment expenses for the only substations and electrical infrastructures of the offshore wind farms represent between 15 and 30\% of the overall investment cost of the project, this leads us to study the optimization of the location of the substation. can reduce these expenses, which also reduces the total cable length inside the wind farm. Our objective is therefore to study the optimization of wind farms with two objective functions aimed at minimizing the costs of installing wind turbines and reducing connectivity between wind turbines using a metaheuristic PSO algorithm.
\end{abstract}

\section{Introduction}

Wind energy is now the second-largest renewable energy source, and it will reach a quarter of the total by 2035, according to the Global Wind Energy Council (GWEC) [1]. A comparative study of onshore wind farms and offshore wind farms shows that offshore wind farms have greater energy production efficiency and are not limited by land occupancy problems. A growing number of academics are focusing their efforts on addressing the Wind Farm Layout Optimization (WFLO) Problem utilizing evolutionary algorithms. An early effort to maximize energy outputs or minimize total losses inside a wind farm was made using evolutionary algorithms without taking the wake effect into account. A multi-objective PSO algorithm is used to minimize the layout costs and optimize energy output without considering the wake effect and discounted costs of a wind farm over its life-cycle [2]. In [3], a genetic algorithm (GA) is used to find the configuration with the least possible power loss (LPC) within the necessary dependability. Similar work is also done by considering the cost and losses of each key component within the wind farm [4].

As a result of the upstream WT impacting downstream $\mathrm{WT}$, the overall energy production of the wind farm is reduced owing to a decrease in wind speed downstream [5]. Wind turbines (WTs) and wind farms (Wind Farms) are becoming more and more powerful as wind energy technology develops. Weighing more, the wake effect has more of an impact on energy yields [6]. The Jensen model, the Ainslie model, and the G.C. Larsen model are the three most popular wake models [7]. With this model, it is expected that a WT's wake would extend linearly and the wind speed inside a wake of different heights will remain constant. This is the first time that Ainslie has created a parabolic eddy viscosity model that includes the turbulent mixing in the wake and ambient turbulence on wake. Due to the fact that results are acquired by solving differential equations, it requires more time to reach the answer and is better suited for dynamic study of WTs. Larsen constructs a semianalytic wake model. As described in [8], the model is recommended for tackling the wake loading problem [9, 10]. Ris National Laboratory has also been working on establishing a new model for predicting the energy outputs of wind farms. In [9], an analytical model is presented, which divides the wake into three distinct regimes and describes the processes of merging of numerous wakes and wake expansion as well as wake striking the ground, etc. As a result of these models, researchers may continue their optimization efforts within the wind farm, taking into account the wake impact. All the models may be used for calculating energy yields, but Jensen model [11]-[12] is the most often used for wind farm layout planning. This is because the Jensen model takes the shortest computing time compared to the other models for calculating the energy yield. [13] and [14] indicate that the Jensen model is more accurate in calculating energy yields. Jensen model is selected in this article for the reasons indicated above.

A wind farm is a complicated process that involves many stages. The proper choosing of a location with the suitable wind profile is also part of the procedure. For the design of a wind farm, however, wind meteorological data are not adequate. To ensure the economic and technical viability of the project, it is essential to optimize the placement of each wind turbine, the location of the substations, and the grid

* Corresponding author: bellatabdelouahad@gmail.com 
network, which links the turbines to each other and to the substation and collects the produced electricity.

In addition, many studies have studied the wake effect produced by wind turbine blades and their influence on the energy efficiency of wind farms, as in $[15,16]$. As a result, there is still a large research gap in the placement of substations and the layout of cables. Especially in offshore wind farms which are under-explored although they offer many advantages.

In the rest of this article will be devoted to the energy modeling and the cost of the installation of wind turbines, subsequently the study of the optimization of two objective functions aimed at minimizing costs and reducing connectivity between wind turbines at using a metaheuristic PSO algorithm

\section{Wind farm modeling}

\subsection{Wake modeling}

After passing past upstream turbines, a phenomenon called the wake effect occurs (WT). An increase in turbulence and a reduction in wind speed may be observed in the windiest area. Comparatively, wind turbines located downstream of the wake zone generate less energy and need more maintenance. WT placement may be influenced by the wake effect model. A wind farm's layout should also take this into consideration (WFDLO).

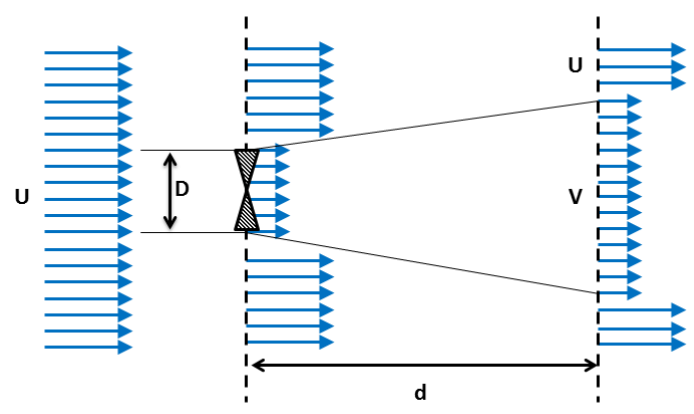

Fig. 1. Jensen wake model .[bb]

Wind speed losses may be shown using several wake models [17-18] which have been created. Analytical wake models and computer wake models, which are at the core of the Navier-Stokes equation's resolution and are more precise than other models, are the two main types. Their use in WFDLO is difficult, however, since they need more calculations and costs. For large WFs with large numbers of WTs, analytic wake models are based on analytical wind speed solutions, which are frequently used in optimization methods. There are a number of different models of wake, but Jensen's is the most often used [19,20]. The Jensen model shown in Figure 1 is compared to other models, [20] shows that this model has high efficiency due to its power loss reliability and excellent prediction accuracy. Our study relies on Jensen's model to calculate different wind speeds. It can be given by equation (1).

$$
V_{d f}=V_{f}\left[\left(1-\sqrt{1-C_{T}}\right)\left(\frac{D}{D_{\text {wake }}}\right)^{2}\right]
$$

Where,

$$
\begin{aligned}
& D: \text { Rotor Diameter }(\mathrm{m}) \\
& D_{\text {wake }}: \text { Wake diameter }(\mathrm{m}) \\
& C_{T}: \text { Trust coefficient } \\
& V_{f}: \text { Free incoming wind speed }(\mathrm{m} / \mathrm{s}) \\
& V_{d f}: \text { Wind velocity deficit }(\mathrm{m} / \mathrm{s})
\end{aligned}
$$

It is anticipated that two turbines will be spaced five times the diameter of their rotors apart in order to reduce wake effects. The following formula expresses this assumption.

$$
\sqrt{\left(x_{i}-x_{j}\right)^{2}+\left(y_{i}-y_{j}\right)^{2}} \leq 5 D
$$

Where,

\section{$D:$ WT (Wind turbine) rotor diameter $(\mathrm{m})$}

$$
\left\{\begin{array}{l}
x_{\min } \leq x_{i} \leq x_{\max } \\
y_{\min } \leq y_{i} \leq y_{\max }
\end{array} \quad \forall \quad i=1,2, \ldots, N\right.
$$

\subsection{Energy modeling}

In order to determine energy production under the wake effect, it is necessary to calculate the power of each wind turbine. Some wind turbine power estimation methods were evaluated in [21]. An approximate estimate of wind turbine energy output is shown below.

$$
P_{W T}=\frac{1}{2} \rho \pi \frac{D^{2}}{4} C_{E F}\left(V_{f}-V_{d f}\right)^{3}
$$

Where,

$C_{E F}$ represents the efficiency factor expressed in equation (4):

$$
C_{E F}=C_{p} \eta_{m} \eta_{g}
$$

In this research, the $\mathrm{C} \mathrm{EF}$ is considered to be 40 percent. The total power generated by wind turbines operating under the wake effect is :

$$
P_{W F}=\sum_{i=1}^{N_{t}} P_{W T}
$$

The following equation describes the efficiency of the wind farm:

$$
\eta_{W F}=\frac{P_{W F}}{\left(\frac{1}{2} \rho \pi \frac{D^{2}}{4} C_{E F} V_{f}^{3}\right)}
$$

In order to assist in the optimization of the studied wind farm, the locations of the wind turbines are provided in Cartesian coordinates $(\mathrm{x}, \mathrm{y})$, the distances between the turbines, and the overall wind speed deficit, which includes overlapping zones, is used. [22,23] describes the total velocity decrease as follows:

$$
V_{d f t}=\sqrt{\sum_{i=1}^{N_{u p}}\left(\frac{A_{O V}}{A}\right)\left(V_{d f}\right)^{2}}
$$

Equation (7) [24] expresses the power losses in a threeconductor AC cable as a function of the square of the 
current flow, the resistance of the cable conductor (Rc) and the length of the cable (L):

$$
P_{\text {loss }}=3 \sum_{i=1}^{N} R_{i} l_{i}(i \times I)^{2}
$$

$R_{i}$ is the resistance of the conductor in the $\mathrm{i}$-th cable segment, and $l_{i}$ is the length of that cable section.

\subsection{Cost modeling}

The original investment cost for the inter-array and export power lines, as well as the transformer at the offshore substation, is included in the cost. equation (9) also includes amortization, which is calculated by taking into account the FOWF's anticipated lifespan.

$C_{\text {acquisition }}=\left(\sum_{1}^{N_{i a c}}\left(C_{i a c} * L_{i a c}+C_{a u x}\right)+\right.$

$\left.\sum_{1}^{N_{\text {exc }}}\left(C_{\text {exc }} * L_{\text {exc }}+C_{\text {aux }}\right)+\sum_{1}^{N_{t}} C_{t}\right) *\left(T \frac{i(1+i)^{T}}{(1+i)^{T}-1}\right)$

The cost per meter of the inter-array cables is $C_{i a c}$, while the length of the cables used to link the FOWTs and the offshore substation is $L_{i a c}$. Similarly, $C_{\text {exc }}$ determines the cost of the export cable and Lexc determines its length. $C_{a u x}$ considers the expense of auxiliary equipment like as buoyancies, bend stiffners, and connections while designing the dynamic power cable. $C_{t}$ determines the transformer's price. $N_{i a c}, N_{e x c}$, and $N_{t}$, respectively, specify the number of inter-array, export cables, and transformers. The interest rate utilized in the amortization computation is determined by $i$.The installation cost includes the cost of running electricity lines and is calculated as follows:

$C_{\text {installation }}=\left(\left(\sum_{1}^{N_{i a c}}\left(L_{i a c}+\sum_{1}^{N_{\text {exc }}} L_{\text {exc }}\right) * C_{\text {vessel }} *\right.\right.$

$\left.\left.r_{\text {instal }}\right)+C_{M o b / D e m o b}\right) *\left(T \frac{i(1+i)^{T}}{(1+i)^{T}-1}\right)$

The cable laying vessel's day rate is $C_{\text {vessel }}$, while the installation rate, rinstal, is expressed in days per meter. The vessel's mobilization and demobilization expenses are specified by a single fixed fee $C_{M o b} /{ }_{\text {Demob }}$.

The cost of energy losses in the cables may be calculated by using the following formula:

$C_{\text {loss }}=\left(\sum_{1}^{\text {Niac }}\right.$ Eloss $_{\text {iac }}+\sum_{1}^{\text {Niac }}$ Eloss $\left._{\text {exc }}\right) * C_{\text {energy }}$

The energy losses in the inter-array and export cables, respectively, are Eloss iac $_{\text {and }}$ aloss exc $_{\text {. The numbers }}$ Niac and Nexc refer to the number of inter-array and export cables, respectively. The total cost of energy losses is calculated by multiplying the total cost of energy losses by the cost per unit of energy $C_{\text {energy }}$. EENS may be calculated by using the following formula:

$C_{E E N S}=T \sum_{k=1}^{n} P_{k}^{\text {cons }} * U_{k} * C_{\text {energy }}$

\section{Methodology}

\subsection{Objective function}

An offshore substation is a transformer platform used for offshore wind farms. Electrical energy from the offshore wind farm to the mainland will be transmitted more efficiently with this substation. There are hundreds of wind turbines in a single offshore wind farm. They are linked by underwater cables, known as feeders, that are placed in a ring or radial arrangement inside the wind farm to the transformer substation. The transformer substation is located at the center of the wind farm. Figure 2 illustrates the radial wind farm topology, as well as the ring structure.

In this paper we will study the optimization of two objective functions.1st function aims at minimizing the cost and maximizing the power, and the second aims at minimizing the interconnection distances between the turbines and the substation.

The two FOBJ objective functions are calculated as follows:

$$
\begin{aligned}
F O B J_{1} & =\min \left(\frac{C_{\text {acquisition }}+C_{\text {installation }}+C_{\text {loss }}+C_{E E N S}}{P_{W F}}\right)(13) \\
F O B J_{2} & =\min \left(D_{s s, w t}\right) \\
& =\min \left(\sum_{i=1}^{N} \sqrt{\left(x_{s s}-x_{w t_{i}}\right)^{2}+\left(y_{s s}-y_{w t_{i}}\right)^{2}}\right)
\end{aligned}
$$

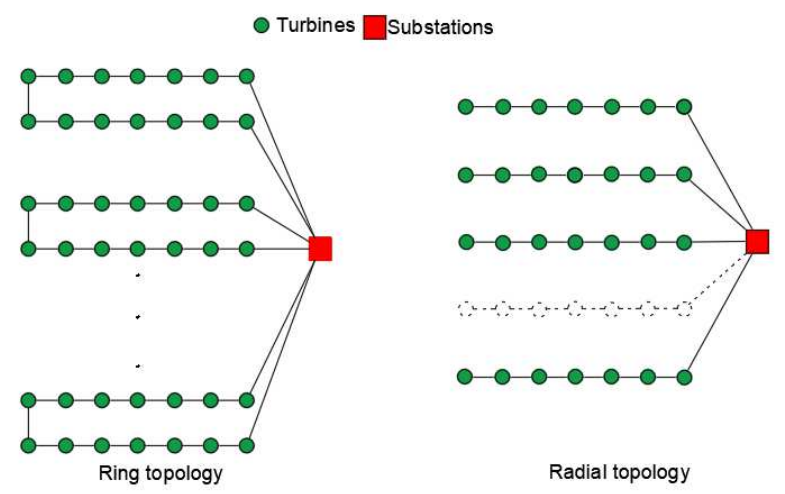

Fig. 2. Illustration of radial and ring topology.[31]

\subsection{Optimization Algorithm}

R. Eberhardt and J. Kennedy [25] created Particle Swarm Optimization, a metaheuristic optimization that consists of a swarm of individuals who are influenced by basic communication processes in their proximity. The swarm and its emergence are now used to determine the optimum of a fitness function, but instead to simulate bird flying. In [26], Kennedy and Eberhardt provide a model based on three basic processes that essentially defines swarm intelligence. They include population adaptability and, as a consequence of assessment, comparison, and imitation, optimization. They think of the swarm as having two parts: a "low-level" component that represents individual behavior and communication processes, and a "high-level" component that depicts 
complex structures and ordering, in this instance, the emergent resultant strategy to reach an optimum.

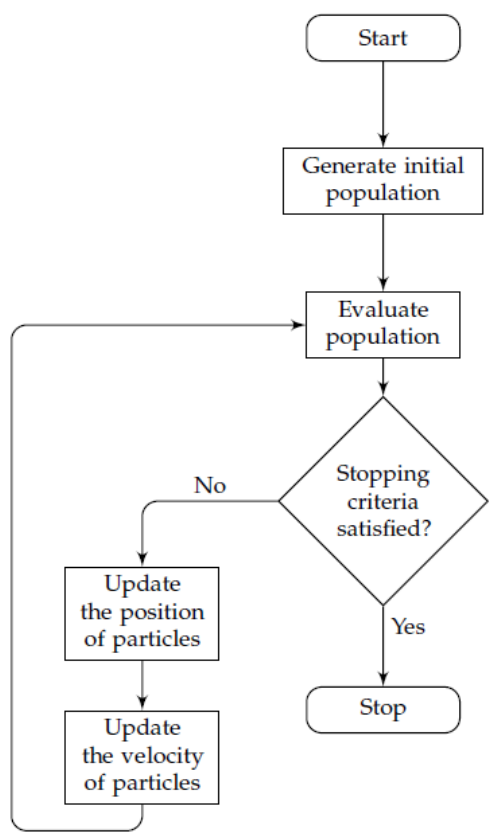

Fig. 3. PSO algorithm applied.

The algorithm proposed in Figure 3 applies these three processes to a particle swarm in order to optimize the resulting emerging effect. Each particle is represented by its location within the search area and its speed, as if the swarm were an actual swarm of birds or fish traveling at different speeds. All particles change their locations and speeds, as well as their trajectories, in order to reach the optimal positions, depending on which particle has the best position within the swarm and their current position. In reality, each particle is affected by the experiences of the other particles in the swarm as well as its own.

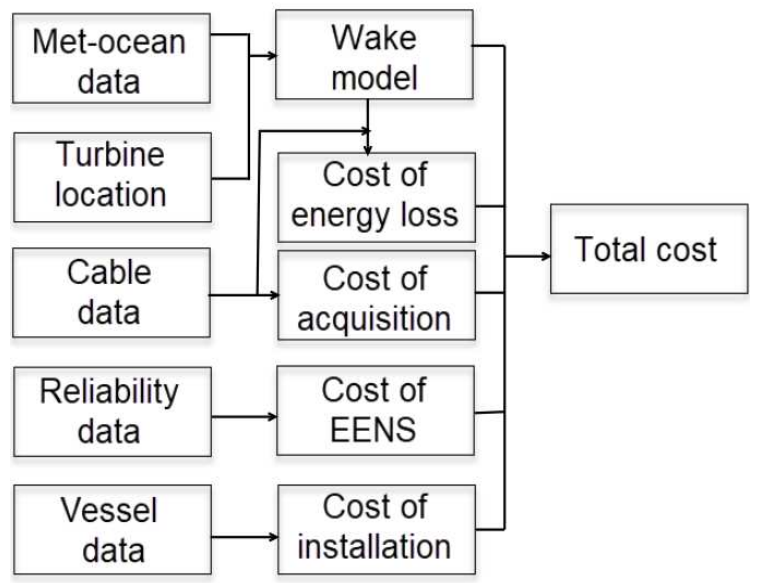

Fig. 4. Different costs associated with energy loss in cables.
Based on PSO theory, the optimization model has been developed in MATLAB and tailored to address the collection grid optimization issue presented in this article. Figure .3 shows the algorithm. Wind farm layout information such as the placement of wind turbines is input into the PSO model during initialization. An initial population of particles with a three-dimensional position matrix is generated next.

Figure 4 illustrates the different costs associated with energy loss in cables.

\subsection{Case study: Barrow offshore wind farm and horns rev offshore wind farm}

In this study we will apply the $F O B J_{1}$ on the Barrow Offshore Wind Farm which consists of a 30 turbine, 90 MW capacity offshore wind farm in the eastern Irish Sea, approximately 7 kilometers southwest of Walney Island, near from Barrow-in-Furness, Cumbria, England. The construction of the wind farm took place between 2005 and 2006. Figure.5 shows the wind turbine locations (WT) and offshore substation locations (OSS) at Barrow offshore wind farm.

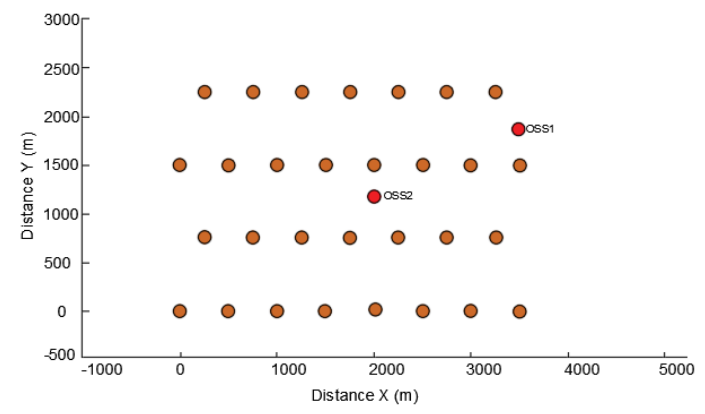

Fig. 5. Locations of wind turbines (WT) and offshore substations (OSS) at the Barrow offshore wind farm.

The second $\mathrm{FOBJ}_{2}$ will be applied to Horns Rev 1 wind farm which is located $20 \mathrm{~km} 2$ in Denmark and which has been in operation since the end of 2002.The collector topology is radial, and the substation is situated outside of the turbine array, thus it is a good example for verifying and demonstrating the dependability of the optimization method. Table 1 [27] has more information on this wind farm.

Table 1. Specifications of wind turbines in Horns-rev1

\begin{tabular}{|c|c|}
\hline Specification & Value \\
\hline Number of turbines & 80 \\
\hline Wind farm capacity & $160 \mathrm{MW}$ \\
\hline Wind turbine capacity & $2 \mathrm{MW}$ \\
\hline $\begin{array}{c}\text { Annual energy } \\
\text { production }\end{array}$ & $600 \mathrm{GWh}$ \\
\hline Turbine model & Vestas $80-2$ \\
\hline
\end{tabular}

The wind turbines are placed in a regular arrangement of 8 rows and 10 columns with the inter-distance between the wind turbines equal to 7 times the diameter of the rotor for a wind direction equal to $0^{\circ}$ as shown in Figure 6. 


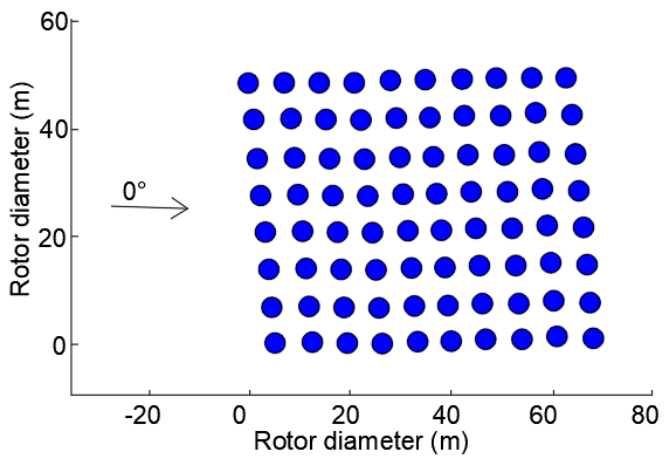

Fig. 6. Presentation of the Horns-rev 1 marine wind farm [28].

\section{Results and discussion}

\section{1 case study: optimization of Barrow offshore wind farm by $F O B J_{1}$}

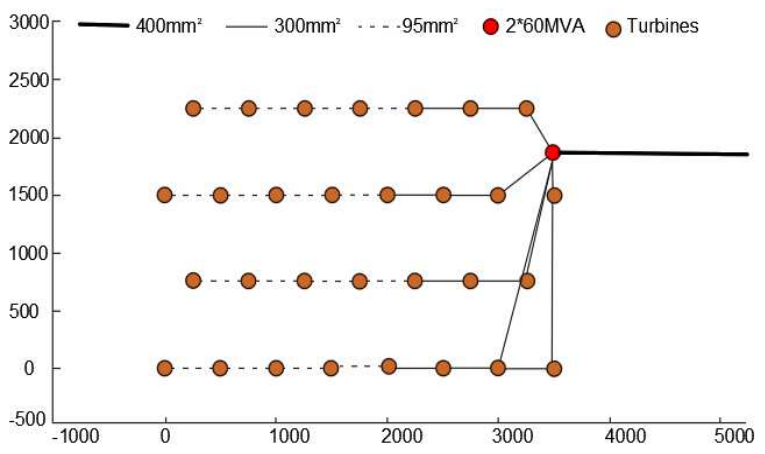

Fig. 7. PSO implementation uses an optimized layout.

[29] contains the information about power cables that was utilized as input data for this case study. Using 10 particles and 20 iterations, the PSO algorithm is applied to the Barrow BOWF. Figure.7 shows the pattern of the cable routing achieved via optimization. This was anticipated, as a result of the restriction of connecting to cables. nearby wind turbines.

Due to the fact that less of the more costly export cable is utilized, expenses and energy losses are minimized. As a result of the optimization model, two transformers with 60MVA each were installed. This is mostly owing to the fact that EENS has reduced expenses due to transformer failure. When only one big transformer breaks, the wind farm's power output is gone, but a smaller transformer may still provide half of the entire electricity. The simplified PSO model produces the same electrical architecture as [30].

Table 2. Comparison of costs.

\begin{tabular}{|c|c|c|c|}
\cline { 2 - 4 } \multicolumn{1}{c|}{} & $\begin{array}{c}\text { Optimization } \\
\text { results by the } \\
\text { new approach }\end{array}$ & $\begin{array}{c}\text { MIQCP } \\
{[12]}\end{array}$ & $\begin{array}{c}\text { Full PSO } \\
{[29]}\end{array}$ \\
\hline $\begin{array}{c}\text { Acquisition cost } \\
(\mathrm{M} €)\end{array}$ & 24.68 & 25.23 & 24.71 \\
\hline $\begin{array}{c}\text { Cost of EENS } \\
\text { (M€) }\end{array}$ & 6.25 & 5.29 & 6.36 \\
\hline $\begin{array}{c}\text { Cost of energy } \\
\text { loss (M€) }\end{array}$ & 4.11 & 4.09 & 4.17 \\
\hline Total cost (M€) & 35.02 & 34.61 & 35.24 \\
\hline $\begin{array}{c}\text { Inter-array length } \\
\text { (km) }\end{array}$ & 16.10 & 17.04 & 16.60 \\
\hline
\end{tabular}

As shown in Table 2, the expenses associated with this provision of the collecting grid are compared to the findings of the baseline study's MIQCP model. In the MIQCP model, the PSO model's acquisition cost is identical to the MIQCP model's. An apparent discrepancy between EENS and energy losses may be observed due to variations in the technique for estimating power losses as well as how wind speed dispersion is taken into consideration. In the computation of energy production, this is taken into consideration. As a result, our method is deemed valid with the previously specified $F O B J_{1}$.

In this case, it is clear that the wires are not crossed. For the first five wind turbines, our model also uses a smaller cable segment, as illustrated in Table 2. Additional savings are achieved via a shorter inter-network cable length, which reduces both acquisition costs and energy losses.

\section{2 case study: optimization of Horns Rev 1 wind farm by $\mathrm{FOBJ}_{2}$}

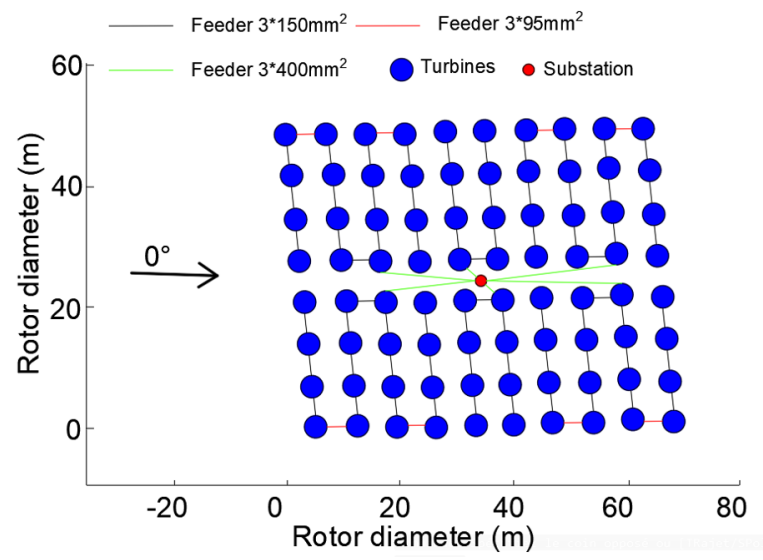

Fig. 8. Optimal location of the substation with change of cable type

Figure. 8 depicts the wind farm's cable optimization. The reported cable length is 10.47 kilometers, or 17.90 $\%$ of the entire length of the original line. Three kinds of AC cable are used in the Horns Rev 1 collector architecture. Two cross-linked polyethylene (XLPE) underwater cables with sections of $3 \times 150 \mathrm{~mm} 2$ and 3 $\times 95 \mathrm{~mm} 2$ are used for departing between the wind turbines, while a length of $3 \times 400 \mathrm{~mm} 2$ is utilized for the export cable between the wind turbine and the substation. The projected costs for the two kinds of cables are $130 € /$ meter, 90€/meter, and $230 € /$ meter, respectively. At the same time, regardless of the cable type, the installation cost per vessel is projected to be $250 € / \mathrm{m}$. Table 3 illustrates the significant savings achieved by increasing the number of cable types and improving the location of the substation in the Horns Rev 1 offshore wind project. 
Table 3. Comparison of cost and cable optimization

\begin{tabular}{|c|c|c|c|c|}
\hline $\begin{array}{c}\text { Cross-section of a } \\
\text { cable }\left(\mathrm{mm}^{2}\right)\end{array}$ & $3 \times 150$ & $3 \times 400$ & $3 \times 95$ & Total \\
\hline $\begin{array}{c}\text { Initial cable } \\
\text { length (Km) }\end{array}$ & 42.06 & 16.44 & $\mathrm{ND}$ & 58.50 \\
\hline $\begin{array}{c}\text { Cost of initial } \\
\text { cable length (K€) }\end{array}$ & 15982.8 & 7891.2 & $\mathrm{ND}$ & 23874 \\
\hline $\begin{array}{c}\text { Optimal cable } \\
\text { length (Km) }\end{array}$ & 38.09 & 6.54 & 3.4 & 48.03 \\
\hline $\begin{array}{c}\text { Cost of optimal } \\
\text { cable length (K€) }\end{array}$ & 14446.1 & 3139.2 & 918 & 35.24 \\
\hline$\Delta$ costs (K€) & -1596.13 & -4752 & +918 & -5430.13 \\
\hline
\end{tabular}

It is also noted that there is a reduction in power losses in the new configuration of the station and with the modification of the type of cable compared to previous studies [31].

\section{Conclusion}

The optimization of wind farms with two objective functions aiming at minimizing expenses and decreasing connectivity between wind turbines was described in this paper using a modified metaheuristic PSO algorithm. The model is very complicated since it takes into consideration the stochastic nature of wind speed and direction, as well as all possible wind turbine connections. A complete wake template is also provided. In addition, the dynamic power cables utilized for the connection, as well as their corresponding purchase and installation expenses, are taken into consideration. The assessment of electrical component dependability and its impact on energy output are also taken into consideration. Several case studies were used to test the PSO concept (optimization of costs and optimization of interconnections between turbines). The results obtained were used to validate the model, which showed an improvement in the cost per unit of power generated by the wind farm when compared to the initial solution. The study also showed an improvement in cost and power by minimizing the distances between the turbines installed in the wind farm studied.

In the extension of this paper, we will aim to apply the same approach in a wind farm containing different types of wind power.

\section{References}

1. Global Wind Report. [Online]. Available: http://www.gwec.net/.

2. Veeramachaneni, Markus Wagner, Una-May O’Reilly, Frank Neumann, “Optimizing Energy Output and Layout Costs for Large Wind Farms using Particle Swarm Optimization," Evolutionary Computation (CEC), 2012 IEEE Congress, pp. 17, Jun. (2012).

3. Zhao, M., Chen, Z., Blaabjerg, F.,'Optimization of electrical system for offshore wind farm via genetic algorithm," Renewable Power Generation, IET, vol. 3, pp. 205-216.

4. Bahirat Nandigam, M. Dhali S.K., "Optimal design of an offshore wind farm layout," Power
Electronics, Electrical Drives, Automation and Motion, 2008, SPEEDAM 2008 International Symposium, pp. 1470-1474, Jun. (2008).

5. Youjie Ma, Haishan Yang, Xuesong Zhou and Li $\mathrm{Ji}$, "The dynamic modeling of wind farms considering wake effects and its optimal distribution," World Non-Grid-Connected Wind Power and Energy Conference, 2009. WNWEC 2009, pp. 1-4, Nanjing, Sep. (2009).

6. Tahavorgar, A., Quaicoe, J.E., "Estimation of wake effect in wind farms using design of experiment methodology," Energy Conversion Congress and Exposition (ECCE), 2013 IEEE, pp. 3317-3324, Sep. (2013).

7. Hou, P., Zhu, J., Ma, K., Yang, G., Hu, W., \& Chen, Z. A review of offshore wind farm layout optimization and electrical system design methods. In Journal of Modern Power Systems and Clean Energy (Vol. 7, Issue 5, pp. 975-986). Springer Heidelberg. (2019).

8. G.C.Larsen, J. Højstrup and H.A. Madsen, "Wind Fields in Wakes," EUWEC '96, Gothenburg, (1996).

9. Sten Frandsen, Rebecca Barthelmie, Sara Pryor, Ole Rathmann, Søren Larsen, Jørgen Højstrup and Morten Thøgersen, "Analytical Modelling of Wind Speed Deficit in Large Offshore Wind Farms," Wind Energ. 2006, pp. 39-53, Jan. (2006).

10. Frandsen, S., Barthelmie, R.J., Pryor, S.C., Rathmann, O., Larsen, S.E., Højstrup, J., Nielsen, P. and Thøgersen, M.L., "The necessary distance between large wind farms offshore - study," Ris $\varnothing$ R-1518(EN) (2005).

11. Wu Yuan-Kang, Lee Ching-Yin, Chen Chao-Rong, Hsu Kun-Wei, Tseng Huang-Tien, “Optimization of the wind turbine layout and transmission system planning for a large-scale offshore wind farm by AI technology," Industry Applications Society Annual Meeting (IAS), 2012 IEEE, pp. 1-9, 7-11 Oct. (2012).

12. A. Kusiak, H. Zheng, "Optimization of wind turbine energy and power factor with an evolutionary computation algorithm," Renewable Energy, Vol. 35, pp. 685-694, Mar. (2010).

13. Yunus Eroğlu, Serap Ulusam Seçkiner, "Design of wind farm layout using ant colony algorithm," Renewable Energy, Vol. 44, pp. 53-62, Aug. (2012).

14. Beatriz Pérez, Roberto Mínguez, Raúl Guanche, "Offshore wind farm layout optimization using mathematical programming techniques," Renewable Energy, Vol. 53, pp. 389-399, May (2013).

15. Sittichoke Pookpunt, Weerakorn Ongsakul, "Optimal placement of wind turbines within wind farm using binary particle swarm optimization with time-varying acceleration coefficients," Renewable Energy, Vol. 55, pp. 266-276, Jul. (2013).

16. Gao, X.; Yang, H.; Lu, L.; Koo, P.Wind turbine layout optimization using multi-population genetic algorithm and a case study in Hong Kong offshore. J. Wind Eng. Ind. Aerodyn. (2015). 
17. Wu, X.; Hu,W.; Huang, Q.; Chen, C.; Chen, Z.; Blaabjerg,F.optimized placement of onshoreWind Farms Considering Topography. Energies (2019).

18. N.A. Andersen, S.J. Sørensen, J.N. Shen, Analysis of turbulent wake behind a wind turbine, Lyngby, 2013.

19. R. Shakoor, M.Y. Hassan, A. Raheem, Y.K. Wu, Wake effect modeling: A review of wind farm layout optimization using Jensen's model, Renewable and Sustainable Energy Reviews, 58, 1048-1059, (2016).

20. L. Wang, A.C.C. Tan, M. Cholette, Y. Gu, "Comparison of the effectiveness of analytical wake models for wind farm with constant and variable hub heights," Energy Conversion and Management, 124, 189-202, (2016).

21 H. Sun, X. Gao, H. Yang, A review of full-scale wind-field measurements of the wind-turbine wake effect and a measurement of the wake-interaction effect, Renewable and Sustainable Energy Reviews, 132, 110042, (2020).

22. P. S. Valverde, A. J. N. A. Sarmento, and M. Alves, "Offshore wind farm layout optimization - State of the art," Proc. Int. Offshore Polar Eng. Conf., vol. 1, no. 1, pp. 157-163, (2013).

23. C. Carrillo, A.F. Obando Montaño, J. Cidrás, E.Díaz-Dorado, Review of power curve modelling for wind turbines, Renewable and Sustainable Energy Reviews, 21, 572-581, (2013).

24. J. Feng, W.Z. Shen, "Wind farm layout optimization in complex terrain: A preliminary study on a Gaussian hill," in Journal of Physics: Conference Series, Institute of Physics Publishing, (2014).

25. T. Göçmen, P. Van Der Laan, P.E. Réthoré, A.P. Diaz, G.C. Larsen, S. Ott, Wind turbine wake models developed at the technical university of Denmark: A review, Renewable and Sustainable Energy Reviews, 60, 752-769, (2016).

26. Hou P, Hu W, Chen Z. Optimisation for offshore wind farm cable connection layout using adaptive particle swarm optimisation minimum spanning tree method. IET Renew Power Gener (2016).

27. Li DD, He C, Fu Y. Optimization of internal electric connection system of large offshore wind farm with hybrid genetic and immune algorithm. In: 2008 Third International Conference on Electric Utility Deregulation and Restructuring and Power Technologies; (2008).

28. El Mokhi, C.; Addaim, A. Optimal Substation Location of a Wind Farm Using Different Metaheuristic Algorithms. In Proceedings of the 6th IEEE International Conference on Optimization and Applications (ICOA2020), Beni Mellal, Morocco, 20-21 April (2020).

29. Lerch, M., De-Prada-Gil, M., \& Molins, C. A metaheuristic optimization model for the interarray layout planning of floating offshore wind farms. International Journal of Electrical Power and Energy Systems, 131. (2021).

30. Banzo, M., \& Ramos, A. Stochastic optimization model for electric power system planning of offshore wind farms. IEEE Transactions on Power Systems, 26(3), 1338-1348. (2011).

31. Mokhi, C. el, \& Addaim, A. Optimization of wind turbine interconnections in an offshore wind farm using metaheuristic algorithms. Sustainability (Switzerland), 12(14), 1-24. (2020). 